\title{
Late-onset multiple acyl-CoA dehydrogenase deficiency mimicking myositis in an elderly patient: a case report
}

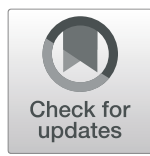

Yiming Zheng, Yawen Zhao, Wei Zhang ${ }^{*}$, Zhaoxia Wang and Yun Yuan

\begin{abstract}
Background: Late-onset multiple acyl-CoA dehydrogenase deficiency (MADD) is a rare and treatable inherited lipid storage myopathy. Here, we report an elderly patient with MADD mimicking myositis.

Case presentation: An 80-year-old woman had progressive weakness in her limbs, exercise intolerance, and no muscle pain for 3 months. The patient's serum creatine kinase level was slightly elevated. The initial diagnosis was myositis. However, muscle biopsy showed many cytoplasmic vacuoles stained with oil red $\mathrm{O}$, indicating the presence of lipid storage myopathy. The plasma acylcarnitine profile showed increased medium-chain and longchain acylcarnitine species, consistent with the diagnosis of MADD. Riboflavin treatment dramatically improved muscle weakness.
\end{abstract}

Conclusions: MADD should be considered when evaluating elderly patients with subacute muscle weakness.

Keywords: MADD, Myositis, Lipid storage myopathy, Case report

\section{Background}

Late-onset multiple acyl-CoA dehydrogenase deficiency (MADD) is a rare heterogeneous inherited disease of fatty acid oxidation that can cause neuromuscular symptoms in adults and responds well to riboflavin treatment [1]. MADD is difficult to diagnose in elderly patients and may be missed without a muscle biopsy [2]. Here, we describe a case of elderly-onset MADD mimicking myositis, highlighting the need to be alert for hereditary myopathy, especially MADD, as a differential diagnosis of myositis in elderly patients.

\section{Case presentation}

An 80-year-old Chinese woman presented with progressive weakness in the proximal limbs and exercise intolerance for 3 months. She had difficulties in climbing stairs and getting up from a chair and needed to rest after walking about $100 \mathrm{~m}$. Her symptoms continued to worsen. Two months before admission, it was difficult for the patient to raise her arms to collect objects or comb her hair. She could only walk about $10 \mathrm{~m}$ unassisted. She also complained of numbness in her toes and fingers. She had no ptosis and no difficulty chewing or swallowing. She exhibited no skin rashes, muscle pain, or weakness fluctuations. The patient had lost about 10 $\mathrm{kg}$ of weight in the past year. She had a 10-year history of hypertension. She used sertraline to treat anxiety for about 3 years. She had no history of myopathy or taking statins. Her family history was unremarkable. Neurological evaluation showed a waddling gait and muscle weakness in the patient's neck flexors and bilateral proximal limbs (4/5 by Medical Research Council scale). No sensory abnormality was found. Serum creatine kinase

\footnotetext{
* Correspondence: neurozw@163.com

Neurology Department, Peking University First Hospital, No. 8 Xishiku Street, Xicheng District, Beijing 100034, China
}

(c) The Author(s). 2020 Open Access This article is licensed under a Creative Commons Attribution 4.0 International License, which permits use, sharing, adaptation, distribution and reproduction in any medium or format, as long as you give appropriate credit to the original author(s) and the source, provide a link to the Creative Commons licence, and indicate if changes were made. The images or other third party material in this article are included in the article's Creative Commons licence, unless indicated otherwise in a credit line to the material. If material is not included in the article's Creative Commons licence and your intended use is not permitted by statutory regulation or exceeds the permitted use, you will need to obtain permission directly from the copyright holder. To view a copy of this licence, visit http://creativecommons.org/licenses/by/4.0/. The Creative Commons Public Domain Dedication waiver (http://creativecommons.org/publicdomain/zero/1.0/) applies to the data made available in this article, unless otherwise stated in a credit line to the data. 

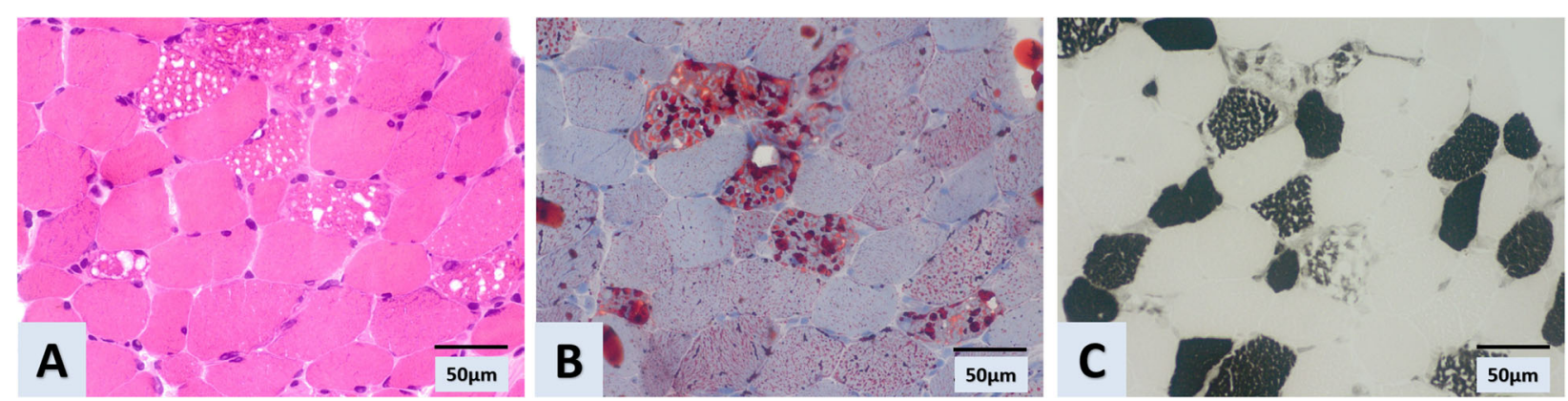

Fig. 1 Muscle biopsy of the vastus lateralis muscle indicating lipid storage myopathy. Light microscopy of muscle biopsy showing muscle fibers containing cytoplasmic vacuoles under hematoxylin and eosin staining (a). Oil red O staining of vacuoles reveals lipid accumulation (b), which mainly appears in type 1 muscle fibers when stained with ATPase pH 4.4 (c)

was slightly elevated at $361 \mathrm{U} / \mathrm{L}$ (reference range 25$170 \mathrm{U} / \mathrm{L})$, and lactate dehydrogenase was also elevated at $500 \mathrm{U} / \mathrm{L}$ (100-240 U/L). Myositis-specific antibody and associated antibody tests showed that the anti-signal recognition particle antibody and anti-Ku antibody were weakly positive (Supplementary Figure S1). A nerve conduction study showed that the conduction velocity of bilateral median and superficial peroneal nerves was decreased. The electromyography and repetitive nerve stimulation were normal. Computed tomography of the chest and abdomen showed no signs of tumors. Magnetic resonance imaging of thigh muscles revealed mild fatty infiltration and edema changes (Supplementary Figure S2).

The initial diagnosis was myositis, and a muscle biopsy was performed to confirm the diagnosis and rule out other myopathies. However, a biopsy of the vastus lateralis muscle showed many cytoplasmic vacuoles under hematoxylin and eosin staining that were confirmed as lipid droplets when stained with oil red O. These mainly appeared in type 1 muscle fibers when stained with ATPase $\mathrm{pH} 4.4$, indicating lipid storage myopathy without any features of myositis (Fig. 1). The plasma acylcarnitine profile under the fed state showed increased medium-chain and long-chain acylcarnitine species (decanoyl $(\mathrm{C} 10)$ carnitines, $0.54 \mathrm{umol} / \mathrm{L}$ (normal range: 0-0.50umol/L); tetradecadienoyl (C14) carnitine, $0.09 \mathrm{umol} / \mathrm{L}(0-0.04 \mathrm{umol} / \mathrm{L})$ and hexadecenoyl (C16) carnitine, $0.48 \mathrm{umol} / \mathrm{L} \quad(0.02-0.42 \mathrm{umol} / \mathrm{L}))$, consistent with the diagnosis of MADD. The patient received oral vitamin B2 (riboflavin) at a dose of $20 \mathrm{mg}$ three times a day. Her muscle weakness gradually improved. After a month of treatment, she regained her normal muscle strength. The patient refused a further genetic test to confirm the genotype.

\section{Discussion and conclusions}

To the best of our knowledge, this report describes the oldest patient ever diagnosed with MADD. The patient had not experienced muscular symptoms previously and began to manifest muscle weakness only in her eighties.

MADD is easily misdiagnosed as myositis [3]. Taking into account the patient's age and subacute onset, progressive weakness of the proximal limbs, elevated creatine kinase, positive anti-signal recognition particle antibody, and edema changes indicated by magnetic resonance imaging of the thigh muscle, the initial diagnosis was myositis, including immune-mediated necrotizing myopathy or sporadic inclusion body myositis. However, exercise intolerance and peripheral nerve damage could not be explained by a diagnosis of myositis. As observed in our patient, MADD can also include distal sensory neuropathy [4]. Early diagnosis is crucial because MADD can be treated with riboflavin supplementation, which may induce a dramatic response [5].

In conclusion, MADD should be included in the differential diagnosis of subacute-onset proximal muscle weakness even in elderly patients, especially those with extreme fatigue. Plasma acylcarnitine profile and urinary organic acid, or muscle biopsy indicating lipid storage myopathy, are important factors to evaluate to avoid overlooking a diagnosis of MADD.

\section{Supplementary Information}

The online version contains supplementary material available at https://doi. org/10.1186/s12883-020-02010-w.

Additional file 1.

Abbreviation

MADD: Multiple acyl-CoA dehydrogenase deficiency

\section{Acknowledgements}

The authors extend their appreciation to the patient for her support. Special acknowledgements to Yuehuan Zuo, Qiurong Zhang, Jing Liu, and Qingqing Wang for their help with the muscle biopsy. We thank Emma LongworthMills, PhD, from Liwen Bianji, Edanz Editing China, for editing the English text of a draft of this manuscript. 


\section{Authors' contributions}

YMZ collected clinical data and drafted the manuscript. YWZ helped to collect clinical data. WZ, ZXW, and YY performed pathological analysis. WZ discussed the results and commented on the manuscript text. The authors read and approved the final manuscript.

\section{Funding}

No specific funding was received from any funding bodies in the public, commercial, or not-for-profit sectors to carry out the work described in this article.

\section{Availability of data and materials}

All data related to this case report are documented within this manuscript.

Ethics approval and consent to participate

Informed consent was obtained from the patient to publish this case report, and approval for this study was provided by the Research Ethics Committee of The First Hospital of Peking University.

\section{Consent for publication}

Written informed consent was obtained from the patient for publication of this case report and any accompanying images. A copy of the written consent is available for review by the editor of this journal.

\section{Competing interests}

The authors declare that they have no competing interests.

Received: 19 September 2020 Accepted: 22 November 2020

Published online: 02 December 2020

\section{References}

1. Prasun P. Multiple acyl-CoA dehydrogenase deficiency. In: Adam MP, Ardinger $\mathrm{HH}$, Pagon RA, et al., eds. GeneReviews ${ }^{\bullet}$. Seattle (WA): University of Washington, Seattle; 1993.

2. Macchione F, Salviati L, Bordugo A, et al. Multiple acyl-COA dehydrogenase deficiency in elderly carriers. J Neurol. 2020;267(5):1414-9.

3. Hong LE, Phillips LK, Fletcher J, Limaye VS. Multiple acyl-CoA dehydrogenase deficiency (MADD) presenting as polymyositis. Rheumatology (Oxford). 2020:keaa348. https://doi.org/10.1093/ rheumatology/keaa348. Epub ahead of print. PMID: 32617583.

4. Wang Z, Hong D, Zhang W, et al. Severe sensory neuropathy in patients with adult-onset multiple acyl-CoA dehydrogenase deficiency. Neuromuscul Disord. 2016;26(2):170-5.

5. Xu J, Li D, LV J, et al. ETFDH mutations and Flavin adenine dinucleotide homeostasis disturbance are essential for developing riboflavin-responsive multiple acyl-coenzyme a dehydrogenation deficiency. Ann Neurol. 2018; 84(5):659-73.

\section{Publisher's Note}

Springer Nature remains neutral with regard to jurisdictional claims in published maps and institutional affiliations. 